\title{
NeuroImage
}

ELSEVIER

\section{Linguistic prominence and Broca's area: The influence of animacy as a linearization principle ${ }^{\frac{\sqrt{T}}{3}}$}

\author{
Tanja Grewe, ${ }^{\mathrm{a}, \mathrm{c}, *}$ Ina Bornkessel, ${ }^{\mathrm{b}}$ Stefan Zysset, ${ }^{\mathrm{b}}$ Richard Wiese, ${ }^{\mathrm{c}}$ \\ D. Yves von Cramon, ${ }^{b}$ and Matthias Schlesewsky ${ }^{a}$ \\ ${ }^{a}$ Research Group Neurolinguistics, University of Marburg, Germany \\ ${ }^{\mathrm{b}}$ Max Planck Institute for Human Cognitive and Brain Sciences, Leipzig, Germany \\ c Department of Germanic Linguistics, University of Marburg, Germany
}

Received 14 November 2005; revised 6 April 2006; accepted 9 April 2006

Available online 12 June 2006

\begin{abstract}
Previous neuroimaging findings suggest a sensitivity of the pars opercularis of the left inferior frontal gyrus (i.e. a core subregion of Broca's area) to a number of linguistic dependencies governing the linear sequencing of information in a sentence (e.g. subjects should precede objects; the participant role hierarchy should be respected). The present study used event-related fMRI to examine the hitherto untested hypothesis that the violation of a linearization principle that is purely semantic in nature (animate arguments should precede inanimate arguments) would also lead to increased pars opercularis activation. To this end, we manipulated the features animacy and argument order in German sentences and found a significant increase of activation in the pars opercularis for a violation of the animacy principle even when the other factors mentioned above were controlled for. This result therefore calls for a "supra-syntactic" account of pars opercularis function in the real-time understanding of sentences.

(c) 2006 Elsevier Inc. All rights reserved.
\end{abstract}

Keywords: Language comprehension; Linearization principles; Argument hierarchization; Animacy; Inferior frontal gyrus; Pars opercularis

\section{Introduction}

Many neuroimaging studies in the domain of sentence comprehension have undertaken manipulations of syntactic complexity in order to identify brain regions that can be related to syntactic processing. However, while syntactic complexity undisputedly plays an important role in determining how easy or difficult a sentence is to understand, it is generally accepted that

\footnotetext{
The research reported here was performed at the Max Planck Institute for Human Cognitive and Brain Sciences, Leipzig.

* Corresponding author. Department of Germanic Linguistics, Philipps University Marburg, Wilhelm-Roepke-Strasse 6A, 35032 Marburg, Germany. Fax: +496421 2824558 .

E-mail address: grewe@staff.uni-marburg.de (T. Grewe).

Available online on ScienceDirect (www.sciencedirect.com).
}

this type of complexity is often accompanied by other influencing factors (Jackendoff, 2002). In particular, the mapping from the surface form of a sentence to its associated meaning is not only governed by syntactic factors (e.g. grammatical functions, Chomsky, 1981), but also by semantic information types (e.g. participant roles, Jackendoff, 1972), and phonological restrictions (e.g. accent placement, Büring, 2001). All of these different factors have been shown to influence the linear ordering of constituents within a sentence and, as such, may play a role in determining how the language processing system accomplishes the form-to-meaning mapping. A crucial question is therefore how these different influencing factors may be dissociated from one another and which status should be attributed to them in a neurocognitive model of language comprehension.

The aim of this paper is to investigate the interaction of three linearization principles using event-related functional magnetic resonance imaging (fMRI). In the following, we will therefore firstly introduce the theoretical foundations for the principles to be examined, before turning to previous neurocognitive results related to this question and introducing the design of the present study.

In languages such as English, the only feature specifying syntactic functions of arguments is their linear position in the sentence. Thus, in declarative sentences, the first argument of a sentence will always be the subject. In contrast, other languages deviate from this principle on account of a wide range of further influences on word order. German, for instance, also shows a preference for a subject-analysis of the first participant (argument) of a sentence, this preferred reading can be overridden by unambiguous morphological case marking (e.g. in Sie wusste, dass dem Studenten die Professoren geholfen hatten; She knew that the student $_{\mathrm{OBJ}}$ the professors ${ }_{\mathrm{SUBJ}}$ helped had). Thus, German allows inverse word orders and morphological marking is the decisive factor in the assignment of the participant roles in sentence interpretation.

But what advantage may be gained by allowing object-initial word orders? The simplest answer to this question appears to be that, under certain circumstances, a violation of the subject-before- 
object principle ("syntactic prominence") serves to satisfy other important principles, thereby providing for a straightforward formto-meaning mapping. Two such "other" principles that are particularly relevant in German are that animate arguments should precede inanimate arguments (henceforth: the animacy principle) and that higher-ranking participant roles should precede lowerranking participant roles (henceforth: the thematic hierarchy principle) (see also Wöllstein-Leisten et al., 1997; Lenerz, 1977). When these principles are violated, the complexity of the form-tomeaning mapping increases.

The importance of animacy in this regard does not appear surprising in view of the exceptional role that this feature plays in determining morphosyntactic patterns in a wide range of languages (Comrie, 1989). For example, animacy not only affects morphological case marking patterns (e.g. in Hindi and Russian) but also determines the linear ordering of arguments in certain languages (e.g. Fore, a language of Papua New Guinea). All of these distinctions follow a universal hierarchy of animacy-based prominence, in which humans are most prominent and inanimate objects are least prominent (Tomlin, 1986). Despite the fact that German morphosyntax does not encode animacy distinctions, the application of the animacy hierarchy is nonetheless apparent in the linear ordering of arguments in this language. Thus, the subjectinitial embedded clause Johanna behauptete, dass der Fotoapparat dem Journalisten entrissen wurde (Johanna claimed that the camera $_{\text {SUBJ+INANIMATE }}$ the journalist OBJ+ANIMATE $_{\text {wrested-from }}$ was) is less marked when the animate object is placed into a position preceding the inanimate subject Johanna behauptete, dass dem Journalisten der Fotoapparat entrissen wurde (Johanna claimed that the journalist OBJ+ANIMATE $_{\text {the camera }}$ SUBJ+INANIMATE wrested-from was). ${ }^{1}$

A second linearization principle of comparably undisputed importance is the thematic hierarchy principle (the "who is acting on whom" principle). Thus, there is a ranking of thematic role prominence, in which thematically higher-ranked (AGENTlike/Actor) arguments always precede lower-ranked (PATIENTlike/Undergoer) arguments (Van Valin and LaPolla, 1997; Jackendoff, 1972). When the thematic prominence of the arguments does not coincide with their syntactic prominence (i.e. when the higher-ranking thematic argument is not also the subject of the sentence), this leads to syntactic restrictions in many languages of the world. In English, for example, sentences of this type (e.g. Bill strikes Harry as pompous) cannot undergo passivization (*Harry was struck by Bill as pompous.) (Jackendoff, 1972, p. 45). Like the animacy hierarchy, the thematic role hierarchy finds a direct correlate in word order preferences in German. Therefore, the subject-initial argument order in Pia glaubte, dass der Dekan dem Professor vorgestellt wurde (Pia

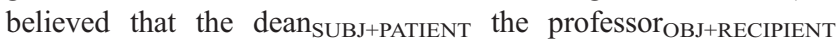
introduced was) is more marked than the corresponding objectinitial order in which the higher-ranking Recipient precedes the lower-ranking Patient: Pia glaubte, dass dem Professor der Dekan vorgestellt wurde (Pia believed that the professor ${ }_{\text {OBJ }+ \text { RECIPIENT }}$ dean $_{\text {SUBJ+PATIENT introduced was). This assumption is theoretically }}$ motivated by the well-established hierarchy of thematic roles: Agent $>$ Recipient $>$ Patient (Jackendoff, 1972).

\footnotetext{
${ }^{1}$ Markedness in this context means that this sentence cannot be uttered "out of the blue". Thus, the marked sentence requires a constraining context (Siwierska, 1988).
}

In the neuroimaging literature, word order variations - and particularly violations of the subject-before-object principle have been closely linked to increased activity of Broca's area (i.e. BA44/45). Thus, there is clear evidence that the activation of Broca's area increases as a function of the number of argument permutations and, thereby, of the number of deviations from the base order subject $>$ indirect object $>$ direct object (Fiebach et al., 2004; Röder et al., 2002). This activation increase corresponds to a reduction in sentence acceptability (Bader and Meng, 1999; Gibson, 1998): the more permutations a sentence involves, the less acceptable it is.

On the one hand, this inferior frontal activation in permuted sentences has been related to syntactic transformations (BenShachar et al., 2003, 2004; Grodzinsky, 2000). Thus, the higher the number of transformations, the higher the activation of Broca's area. On the other hand, some authors consider the effect to be related to working memory demands, which also increase in parallel to the syntactic complexity (Caplan et al., 2000; Kaan and Swaab, 2002; Müller et al., 2003; Fiebach et al., 2005). These costs may either stem from the (syntactic) requirement to reconstruct an underlying base order (Fiebach et al., 2005) or from the inability to associate an initial object with an appropriate meaning until the verb is encountered (Gibson, 1998; Kaan and Swaab, 2002). In this way, despite their conflicting views on the functional significance of Broca's area activation, these two classes of explanations appeal primarily to the relation between subjects and objects.

Recent findings, by contrast, suggest that a characterization of the function of Broca's area and particularly of the pars opercularis of the left inferior frontal gyrus (IFG) in purely syntactic terms is too narrow. Rather, it has been shown that the activation increase in the pars opercularis that arises from violations of the subjectbefore-object principle can be neutralized when the object-initial ordering allows for other linearization principles to be upheld (Bornkessel et al., 2005; Grewe et al., 2005).

Firstly, Bornkessel et al. (2005) demonstrated an influence of the thematic hierarchy principle on the activation of the pars opercularis. These authors found an interaction between this principle and the subject-before-object principle such that a violation of neither principle led to the lowest degree of activation, violations of both principles gave rise to the highest degree of activation and a violation of either one principle or the other was reflected in an intermediate degree of activation within this cortical region.

Secondly, Grewe et al. (2005) demonstrated that the pars opercularis is sensitive to further language-specific principle, which concerns the linearization of pronouns and non-pronominal noun phrases. Following Lenerz (1977), pronouns precede nonpronominal arguments in unmarked German clauses independently of their status as subject or object. This linearization rule is directly reflected in the activation pattern of the pars opercularis, since sentences involving an initial pronominal object, e.g. Dann hat ihm der Lehrer den Spaten gegeben (then has him IOBJ $_{\text {the }}$ teacher $_{\text {SUBJ }}$ the spade $_{\text {DOBJ }}$ given), did not show an activation increase in comparison to the control condition with a nonpronominal subject in the first position. By contrast, compared with the control condition object-initial sentences without pronouns showed the well-known activation increase within the pars opercularis. By contrast, object-initial sentences without pronouns showed the well-known activation increase within the pars opercularis. 
Table 1

Critical sentence conditions in the present experiment

\begin{tabular}{|c|c|}
\hline Condition & Example \\
\hline $\mathrm{OS}_{\mathrm{I}}$ & $\begin{array}{l}\text { Dann } \mid \text { wurde } \mid \text { dem Arzt } \mid \text { der Mantel } \mid \text { gestohlen. } \\
\text { then was }[\text { the doctor }]_{\text {DAT }}[\text { the coat }]_{\text {NOM }} \text { stolen } \\
\text { 'Then the coat was stolen from the doctor.' }\end{array}$ \\
\hline $\mathrm{S}_{\mathrm{I}} \mathrm{O}$ & $\begin{array}{l}\text { Dann } \mid \text { wurde } \mid \text { der Mantel } \mid \text { dem Arzt } \mid \text { gestohlen. } \\
\text { then was }[\text { the coat }]_{\text {NOM }}[\text { the doctor }]_{\text {DAT }} \text { stolen } \\
\text { 'Then the coat was stolen from the doctor.' }\end{array}$ \\
\hline $\mathrm{OS}_{\mathrm{A}}$ & $\begin{array}{l}\text { Dann } \mid \text { wurde } \mid \text { dem Arzt } \mid \text { der Polizist } \mid \text { vorgestellt. } \\
\text { then was }[\text { the doctor }]_{\text {DAT }}[\text { the policeman }]_{\text {NOM }} \text { introduced to } \\
\text { 'Then the policeman was introduced to the doctor.' }\end{array}$ \\
\hline $\mathrm{S}_{\mathrm{A}} \mathrm{O}$ & $\begin{array}{l}\text { Dann } \mid \text { wurde } \mid \text { der Polizist } \mid \text { dem Arzt } \mid \text { vorgestellt. } \\
\left.\text { then was [the policeman }]_{\text {NOM }} \text { [the doctor }\right]_{\text {DAT }} \text { introduced to } \\
\text { 'Then the policeman was introduced to the doctor.' }\end{array}$ \\
\hline
\end{tabular}

Stimulus segmentation is indicated by the vertical bars. Abbreviations used: $\mathrm{OS}=$ object - before - subject (permuted); $\mathrm{SO}=$ subject-before- object (non-permuted); $\mathrm{NOM}=$ nominative; $\mathrm{DAT}=$ dative; $\mathrm{S}_{\mathrm{I}}=$ inanimate subject; $\mathrm{S}_{\mathrm{A}}=$ animate subject.

These results indicate that the activation of the pars opercularis in the processing of argument order variations results from a complex interaction between the subject-before-object principle and a variety of further principles. The aim of the present study is to extend these observations by examining the role of animacy as a linearization parameter. As described above, the influence of animacy on morphosyntactic phenomena may arguably be considered the clearest example that a purely semantic feature can modulate the syntactic behavior of a language. ${ }^{2}$ Therefore, if animacy also affected the activation pattern of the pars opercularis, this would provide the strongest possible evidence that word order complexity effects in this region cannot be characterized in purely syntactic terms.

Consequently, the design of the present study manipulated the factors argument order (subject-object vs. object-subject) and animacy (animacy contrast vs. no animacy contrast between the two arguments). The resulting four critical conditions are illustrated in Table 1.

Crucially, the structures shown in Table 1 allow for a dissociation of the animacy principle from the subject-beforeobject principle and the thematic hierarchy principle. This was accomplished by employing passivized ditransitive structures. These types of sentences induce a conflict between the subjectbefore-object principle and the thematic hierarchy principle, because the subject argument is the thematically lower-ranking Patient, while the object argument is the thematically higherranking Recipient. (On account of the properties of the passive, the Agent argument is not realized.) With respect to the subject-initial structures, this means that the thematic hierarchy principle is violated, while the subject-before-object principle is fulfilled. For the object-initial sentences, by contrast, the thematic hierarchy

\footnotetext{
2 Indeed, previous neurocognitive findings provide converging evidence for the importance of animacy in sentence comprehension. On the one hand, Frisch and Schlesewsky (2001) used event-related brain potentials to show that animacy information interacts with case marking in the online computation of a thematic hierarchy. On the other hand, Weckerly and Kutas (1999) argued that animacy modulates the interpretation of subject arguments in English. This finding is paralleled by recent neuroimaging evidence (Chen et al., to appear).
}

principle is fulfilled, but the subject-before-object principle is violated. As was shown in Bornkessel et al. (2005), a conflict between these two principles leads to a neutralization of the pars opercularis activation increase for object-initial structures. It is precisely this phenomenon that allows us to isolate possible animacy-induced activation changes within the pars opercularis: while condition $\mathrm{OS}_{\mathrm{I}}$ respects the animacy principle, this principle is violated in condition $\mathrm{S}_{\mathrm{I}} \mathrm{O}$. The interaction of the different linearization principles is summarized in Table 2.

Our hypotheses for the present study are therefore as follows. On the basis of the line of argumentation laid out above, we should observe a clear activation increase within the pars opercularis when the animacy principle is violated (i.e. for $\mathrm{S}_{\mathrm{I}} \mathrm{O}$ vs. $\mathrm{OS}_{\mathrm{I}}$ ). However, an interpretation of a difference between these two conditions in terms of animacy presupposes that the two conditions without an animacy contrast $\left(\mathrm{S}_{\mathrm{A}} \mathrm{O} / \mathrm{OS}_{\mathrm{A}}\right)$ do not differ significantly in this region.

\section{Materials and methods}

\section{Participants}

Twenty-one students (9 females; mean age 25.19) participated in the fMRI study. All participants were monolingual, native speakers of German, had normal or corrected-to-normal vision, and were right-handed as indicated by a German version of the Edinburgh Inventory (Oldfield, 1971). Informed written consent was obtained from all participants prior to the scanning session.

\section{Materials}

The sentence stimuli used in this study consisted of four types of grammatically correct German passive sentences (see Table 1 for one sample set of stimuli). In addition to these critical conditions, there were two types of grammatically incorrect German passive constructions to balance out the acceptability for the behavioral task (see below). Each participant read 34 sentences in each of the conditions. All critical sentences comprised a sentence-initial adverb, followed by a finite auxiliary, two arguments, and a clause-final participle. The ungrammatical fillers were of a similar form as the critical sentences but contained an incorrectly positioned participle. Participants thus read a total of 204 sentences. Additionally, 34 null events (empty trials) were introduced to improve statistical evaluation of the data (Miezin et al., 2000), thus resulting in a total number of 238 trials per participant.

\section{Procedure}

All participants read the experimental sentences via LCD goggles (Visuastim; Magnetic Resonance Technology, Northridge,

Table 2

Linearization rules concerning the critical conditions in the present experiment

\begin{tabular}{llll}
\hline & Subject $>$ Object & Recipient $>$ Patient & Animate $>$ Inanimate \\
\hline A. $\mathrm{OS}_{\mathrm{I}}-$ & + & + & + \\
B. $\mathrm{S}_{\mathrm{I}} \mathrm{O}+$ & - & - \\
C. $\mathrm{OS}_{\mathrm{A}}-$ & + & + \\
D. $\mathrm{S}_{\mathrm{A}} \mathrm{O}+$ & - & + \\
\hline
\end{tabular}


CA). Reading strategies were controlled for by presenting all sentences in a segmented manner. Every segment was presented for $400 \mathrm{~ms}$ in the center of the screen with an interstimulus interval (ISI) of $100 \mathrm{~ms}$ (segmentation indicated in Table 1). Each trial began with a presentation of an asterisk (300 ms plus $200 \mathrm{~ms} \mathrm{ISI)}$ and ended with a 500-ms pause. After this, a question mark signaled to participants that a behavioral response was required. Their task was to judge the acceptability of the preceding sentence. This judgment task was carried out by pressing one of two pushbuttons with the right index and middle fingers and the participants were given maximally $2500 \mathrm{~ms}$ to respond. The assignment of fingers to acceptable and unacceptable was counterbalanced across participants. The trials were presented with variable onset delays of $0,400,800,1200$, or $1600 \mathrm{~ms}$, thereby leading to an oversampling of the actual image acquisition time of $2000 \mathrm{~ms}$ by a factor of five (Miezin et al., 2000). Every trial had a length of $8 \mathrm{~s}$, thus resulting in a total measurement time of $32 \mathrm{~min}$, which was separated into two functional runs.

Before entering the scanner each participant completed a short practice session.

\section{fMRI data acquisition}

The experiment was carried out on a $3 \mathrm{~T}$ scanner (Medspec 30/ 100, Bruker, Ettlingen). Twenty axial slices ( $19.2 \mathrm{~cm} \mathrm{FOV,} 64$ by 64 matrix, $3 \mathrm{~mm}$ thickness, $0.6 \mathrm{~mm}$ spacing), parallel to the ACPC plane were acquired using a single shot, gradient recalled EPI sequence (TR $2000 \mathrm{~ms}$, TE $30 \mathrm{~ms}, 90^{\circ} \mathrm{flip}$ angle). As the main focus of the experiment was on the activation of pars opercularis of the IFG, we chose to increase the spatial resolution for this region by means of a reduction in slice thickness and spacing. Consequently, a whole-head coverage was not possible and no signal was acquired for regions such as inferior parts of the cerebellum and superior parts of the frontal and parietal lobes. Two functional runs of 484 time points were collected, with each time point sampling over the 20 slices. Prior to the functional runs, 20 anatomical T1-weighted MDEFT (Ugurbil et al., 1993; Norris, 2000) images (data matrix $256 \times 256$, TR $1.3 \mathrm{~s}$, TE $10 \mathrm{~ms}$ ) and 20 T1-weighted EPI images with the same geometrical parameters as the functional data were acquired.

\section{fMRI data analysis}

The fMRI data were analyzed using the LIPSIA software package (Lohmann et al., 2001). This software contains tools for preprocessing, registration, statistical evaluation and presentation of fMRI data.

First, the functional data were corrected for motion using a matching metric based on linear correlation. To correct for the temporal offset between the slices acquired in one scan, a cubicspline-interpolation based on the Nyquist-Shannon Theorem was applied. A temporal highpass filter with a cutoff frequency of 1/112 $\mathrm{Hz}$ was used for baseline correction of the signal and a spatial Gaussian filter with $5.65 \mathrm{~mm}$ FWHM was applied.

Subsequently, a rigid linear registration with six degrees of freedom (3 rotational, 3 translational) was performed to align the functional data slices onto a $3 \mathrm{D}$ stereotactic coordinate reference system. The rotational and translational parameters were acquired on the basis of the MDEFT and EPI-T1 slices to achieve an optimal match between these slices and the individual $3 \mathrm{D}$ reference data set. This $3 \mathrm{D}$ reference data set was acquired for each subject during a previous scanning session. The MDEFT volume data set with 160 slices and $1 \mathrm{~mm}$ slice thickness was standardized to the Talairach stereotactic space (Talairach and Tournoux, 1988). The same rotational and translational parameters were normalized, i.e. transformed to a standard size via linear scaling. In a next step, the resulting transformation parameters were applied to the functional slices via trilinear interpolation, so that the resulting functional slices were aligned with the stereotactic coordinate system. This linear normalization process was improved by a subsequent processing step that performs an additional non-linear normalization (Thirion, 1998).

The statistical evaluation was based on a least-squares estimation using the general linear model for serially autocorrelated observations (see also Friston et al., 1995; Worsley and Friston, 1995; Aguirre et al., 1997; Zarahn et al., 1997). The design matrix was generated with a box-car function convolved with the hemodynamic response function. The model equation, including the observation data, the design matrix as well as the error term, was convolved with a Gaussian kernel of dispersion of $4 \mathrm{~s}$ FWHM to deal with the temporal autocorrelation (Worsley and Friston, 1995). Thereafter, contrast maps were generated for each subject. As the individual functional data sets were all aligned to the same stereotactic reference space, a group analysis was performed. The single-participant contrast-images were entered into a second-level random effects analysis for each of the contrasts. The group analysis consisted of a one-sample $t$ test across the contrast images of all subjects that indicated whether observed differences between conditions were significantly distinct from zero (Holmes and Friston, 1998). Subsequently, $t$ values were transformed into $Z$ scores. To protect against false positive activations, only regions with a $Z$ score greater than 3.1 ( $P<0.001$ uncorrected $)$ and with a volume greater than $162 \mathrm{~mm}^{3}$ (6 measured voxels) were considered (Braver and Bongiolatti, 2002; Forman et al., 1995).

\section{Results}

\section{Behavioral data}

For the analysis of the behavioral data, repeated-measures of variance (ANOVAs) were computed using the factors animacy (ANI: I vs. A) and word order (ORDER: SO vs. OS). The probability levels for planned comparisons were adjusted according to a modified Bonferroni procedure (Keppel, 1991).

The mean acceptability rates in the behavioral task were: $\mathrm{OS}_{\mathrm{I}}$ (97\%); $\mathrm{S}_{\mathrm{I}} \mathrm{O}(93 \%) ; \mathrm{OS}_{\mathrm{A}}(95 \%) ; \mathrm{S}_{\mathrm{A}} \mathrm{O}(92 \%)$. Thus, there were no main effects for the factors ANI and ORDER in the global analysis $($ ANI $(F(3,60)=1.98 ; P>0.175)$; ORDER $(F(3,60)=1.26 ; P>$ $0.292)$ and no interaction between these two factors could be found (ANI BY ORDER $(F(3,60)=1.09 ; P>0.308))$.

The reaction times showed the following mean values per condition: $\mathrm{OS}_{\mathrm{I}}(523 \mathrm{~ms}) ; \mathrm{S}_{\mathrm{I}} \mathrm{O}(556 \mathrm{~ms}) ; \mathrm{OS}_{\mathrm{A}}(596 \mathrm{~ms}) ; \mathrm{S}_{\mathrm{A}} \mathrm{O}$ (584 $\mathrm{ms})$. While the global analysis again revealed no significant main effects for the factors ANI $(F(3,60)=7.94 ; P>0.11)$ and ORDER $(F(3,60)<1)$, the interaction between both factors was marginally significant (ANI BY ORDER: $F(3,60)=3.31 ; P=0.084$ ). Planned comparisons for each of the levels of ANI revealed a significant difference between $\mathrm{S}_{\mathrm{I}} \mathrm{O}$ and $\operatorname{OS}_{\mathrm{I}}(F(1,20)=4.57 ; P<0.05)$, which resulted from longer reaction times for condition $\mathrm{S}_{\mathrm{I}} \mathrm{O}$ compared to $\mathrm{OS}_{\mathrm{I}}$. There was no significant difference between the conditions with only animate arguments $\left(\mathrm{S}_{\mathrm{A}} \mathrm{O}\right.$ vs. $\left.\mathrm{OS}_{\mathrm{A}}: F(1,20)<1\right)$. 
In this way, the reaction time differences confirm the predictions for the experimental manipulation. The violation of the animacy principle leads to increased reaction times, while there is no difference between the two conditions without an animacy contrast.

\section{$f M R I$ data}

In accordance with our main hypothesis, we first examined the interaction contrast for our two critical factors $\left(\left(\mathrm{S}_{\mathrm{I}} \mathrm{O}-\mathrm{OS}_{\mathrm{I}}\right)-\right.$ $\left.\left(\mathrm{OS}_{\mathrm{A}}-\mathrm{S}_{\mathrm{A}} \mathrm{O}\right)\right)$. This contrast, however, yielded no significant activations at an acceptable significance threshold, possibly due to the very fine-grained linguistic manipulation employed (all critical conditions are highly acceptable and do not give rise to conscious processing difficulty).

On account of our clear prediction with respect to linearization and the pars opercularis, we next conducted a region-of-interest (ROI) analysis in order to test for a possible interaction within the pars opercularis. To this end, we determined the local activation maximum within the pars opercularis from the activation for all four of our critical conditions, i.e. from the contrast between critical conditions and empty trials. In determining local maxima, only activations with a $z$ value $>3.09$ ( $P<0.001$, uncorrected $)$ and a volume of at least $216 \mathrm{~mm}^{3}$ ( 8 measured voxels) were taken into account. Local maxima were defined as voxels with the highest $z$ value exceeding 3.09 within an $8 \mathrm{~mm}$ radius. For the ROI analysis, we extracted the time course of the underlying BOLD-response for the local activation maximum within the pars opercularis (-539 21 ) and the 26 adjacent voxels. The percent signal change (relative to the mean signal intensity over all time points per voxel) inside this region was averaged for each condition and participant. The time course of the null events was subtracted from the averaged single-event time courses for the critical sentence conditions (Burock et al., 1998). The averaged time courses (mean percent signal change for a time window from -2 to +2 relative to the maximal signal change per participant and condition), which are visualized in Fig. 1, were subjected to a repeated measures analysis of variance (ANOVA) involving the factors word order (ORDER; OS vs. SO) and animacy (ANI; I vs. A). This analysis revealed a clear interaction of ORDER $\times$ ANI $(F(1,20)=5.65, P<0.03)$. Planned comparisons for each level of ANI showed a significant effect of ORDER for $\mathrm{S}_{\mathrm{I}} \mathrm{O}$ vs. $\mathrm{OS}_{\mathrm{I}}(F(1,20)=25.57, P<0.001)$ but

\section{IFG (pars opercularis)}

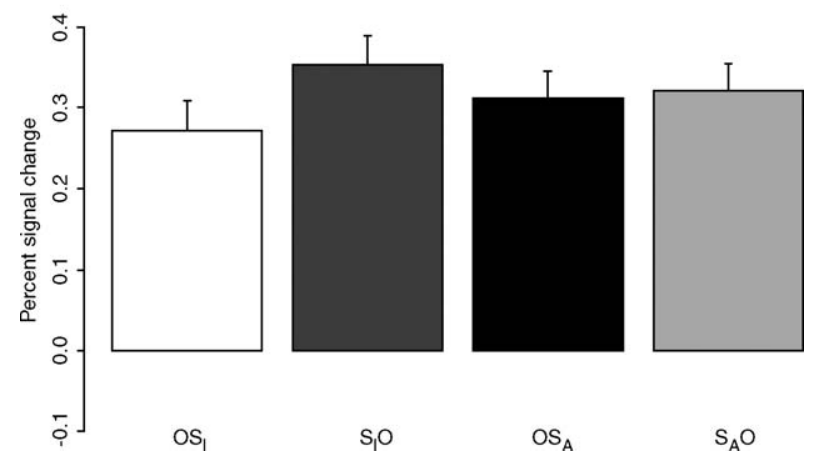

Fig. 1. ROI analysis for the pars opercularis of the left IFG. Average percent signal change ( -2 to $+2 \mathrm{~s}$ relative to the point of maximal signal change) for the activation maximum within this region $\left(\begin{array}{lll}-53 & 9 & 21\end{array}\right)$ and the 26 adjacent voxels. Error bars indicate the standard error of the mean.

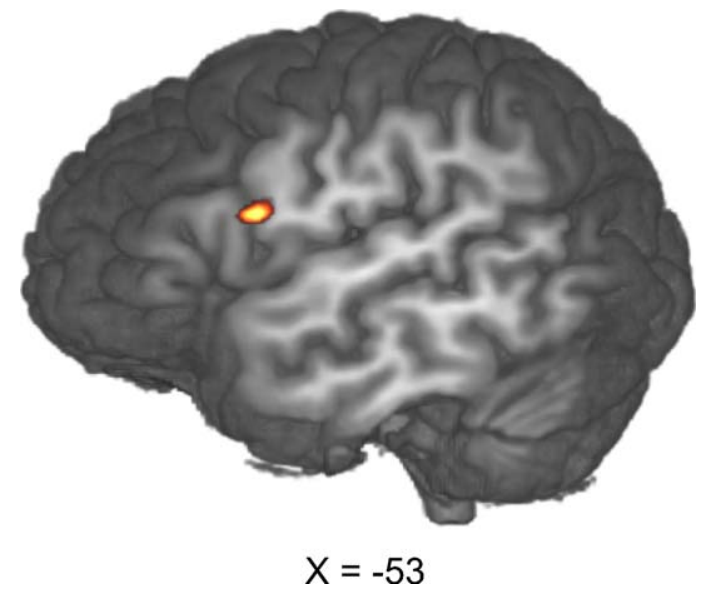

Fig. 2. Averaged activation with a $z$ value $>3.09(N=21)$ for the contrast between the condition with an inanimate subject preceding an animate object $\left(\mathrm{S}_{\mathrm{I}} \mathrm{O}\right)$ and the condition with an animate object preceding an inanimate subject $\left(\mathrm{OS}_{\mathrm{I}}\right)$ after the reaction times have been modeled.

no significant difference between the two conditions with only animate arguments $(F<1)$.

On the basis of the interaction between word order and animacy obtained in the ROI analysis, we computed a direct contrast between the two conditions involving inanimate subjects in different positions $\left(\mathrm{S}_{\mathrm{I}} \mathrm{O}\right.$ vs. $\left.\mathrm{OS}_{\mathrm{I}}\right)$. To ensure that this comparison would not be confounded with reaction time differences (which also contrasted between $\mathrm{S}_{\mathrm{I}} \mathrm{O}$ vs. $\left.\mathrm{OS}_{\mathrm{I}}\right)$ ( $z$-transformed) reaction times per condition and participant were included in the analysis and modeled as a covariate of no interest. As shown in Fig. 2 and Table $3 \mathrm{a}$, this contrast yielded a significant activation within the superior portion of the pars opercularis, with a maximum highly comparable to that examined in the ROI analysis. No other significant activations were observed. To rule out the possibility of false positives, we used a MonteCarlo Simulation (http://www.afni. nimh.nih.gov/afni/doc/manual/AlphaSim) to determine the nonarbitrary voxel cluster size. This simulation provides a means of estimating the probability of a false detection of activated clusters $(<0.05)$ and showed that activations exceeding 5 voxels $\left(135 \mathrm{~mm}^{3}\right)$ have an alpha error of $<0.01$. Thus, while the activation within the pars opercularis is relatively small ( 8 voxels), it indeed appears meaningful. ${ }^{3}$

We also investigated the analogous word order contrast between the conditions with two animate arguments $\left(\mathrm{S}_{\mathrm{A}} \mathrm{O}\right.$ vs. $\left.\mathrm{OS}_{\mathrm{A}}\right)$, but the only activations observable in this contrast were found in superior occipital gyrus of the left hemisphere and in the left and right basal ganglia (BG) (see Table 3b).

In contrast to previous findings on word order variations, the average activation for $\mathrm{S}_{\mathrm{I}} \mathrm{O}$ vs. $\mathrm{OS}_{\mathrm{I}}$ in the present experiment is located in the very posterior portion of the superior part of the pars opercularis. Thus, as Fig. 2 shows, it not only involves the inferior precentral sulcus, but also the anterior portion of the ventral

\footnotetext{
${ }^{3}$ An additional time course analysis for this activation (conducted in an analogous manner to that described for the ROI analysis above) again confirmed the finding of an interaction between animacy and word order $(F(1,20)=6.17, P<0.03)$. This interaction resulted from a significant difference between the two conditions involving one inanimate argument $(F(1,20)=26.23, P<0.001)$, while the two conditions with only animate arguments did not differ from one another $(F<1)$.
} 
Table 3a

Talairach coordinates, maximal $z$ values and volumes of the activated region for the local maxima in the contrast between sentences with an inanimate argument preceding the animate argument $\left(\mathrm{S}_{\mathrm{I}} \mathrm{O}\right)$ and sentences with an animate argument preceding the inanimate argument $\left(\mathrm{OS}_{\mathrm{I}}\right)$ in an analysis including the mean reaction times per condition and participant as regressors

\begin{tabular}{llll}
\hline Region & Talairach coordinates & Molume $\left(\mathrm{mm}{ }^{3}\right)$ \\
\hline L. inferior frontal gyrus (IFG), pars opercularis & -53621 & 216 & 4.01 \\
\hline
\end{tabular}

Only activations with a $z$ value $>3.09$ and a volume of at least $216 \mathrm{~mm}^{3}$ (8 measured voxels) were considered.

premotor cortex. In this context, the effect of possible interindividual variations was also considered. Thus, we examined the critical activation per subject rendered on that subject's individual anatomy against a probability map of the pars opercularis (Tomaiuolo et al., 1999) to ensure that the activation maximum for each single subject was indeed located within this region. This analysis revealed that 17 participants showed the activation peak for the critical comparison in the pars opercularis proper (mean Talairach coordinates $x=51.8, y=13.8, z=17.2$ ), while in 3 participants the activation maximum was found in the pars opercularis but at the border of the precentral gyrus (mean Talairach coordinates $x=53.3, y=8.3, z=27$ ) and 1 participant showed the activation peak in the pars opercularis at the border of the deep frontal operculum $(x=-35, y=9, z=21)$. Thus, on account of the fact that the activation lies in the pars opercularis proper for the vast majority of participants, we will continue to refer to the $\mathrm{S}_{\mathrm{I}} \mathrm{O}$ vs. $\mathrm{OS}_{\mathrm{I}}$ contrast as yielding increased neural activity in the pars opercularis.

To summarize, our results provide consistent evidence that pars opercularis is sensitive to animacy differences in word order variation. Furthermore, the animacy contrast within this region (higher activation for $\mathrm{S}_{\mathrm{I}} \mathrm{O}$ vs. $\mathrm{OS}_{\mathrm{I}}$ ) was not accompanied by an activation difference between the two conditions with only animate arguments $\left(\mathrm{S}_{\mathrm{A}} \mathrm{O} / \mathrm{OS}_{\mathrm{A}}\right)$. Thus, the activation difference must be attributed to the animacy principle rather than to the subject-before-object principle or the thematic hierarchy principle. $^{4}$

\section{Discussion}

In the current experiment, we investigated the impact of animacy, a non-syntactic feature, on the linear ordering of sentential arguments. Sentences with an initial inanimate subject $\left(\mathrm{S}_{\mathrm{I}} \mathrm{O}\right)$ showed increased activation in the superior portion of the pars opercularis of the left IFG in comparison to sentences with an initial animate object $\left(\mathrm{OS}_{\mathrm{I}}\right)$. A control comparison using the identical sentence structures with only animate arguments did not show significant differences in the pars opercularis.

\footnotetext{
${ }^{4}$ Interestingly, we found one additional side-effect. A comparison of the two conditions with only animate arguments $\left(\mathrm{S}_{\mathrm{A}} \mathrm{O} / \mathrm{OS}_{\mathrm{A}}\right)$ with those conditions with one inanimate argument $\left(\mathrm{S}_{\mathrm{I}} \mathrm{O} / \mathrm{OS}_{\mathrm{I}}\right)$ showed an activation increase in the left posterior superior temporal sulcus for the conditions containing only animate arguments (mean Talairach coordinates $x=-47$, $y=-48, z=21$ ). This finding might be interpreted in terms of an engagement of this cortical region in the processing of agency (Frith and Frith, 1999) and appears compatible with previous findings revealing an interaction of syntactic and semantic information in the left posterior superior temporal sulcus (Friederici et al., 2003; Bornkessel et al., 2005; Scott and Johnsrude, 2003).
}

Firstly, these results replicate the finding reported in Bornkessel et al. (2005). These authors argued that the activation pattern of the pars opercularis reflects the interaction between the subjectbefore-object principle and the thematic hierarchy principle, because sentence types violating either one or the other of these principles did not yield activation differences within this region. This observation is confirmed by the interaction between animacy and word order observed in the present study: whereas our control comparison between sentences involving two animate arguments $\left(\mathrm{S}_{\mathrm{A}} \mathrm{O} / \mathrm{OS}_{\mathrm{A}}\right)$ did not lead to a significant activation difference within the pars opercularis, the conditions involving an animacy variation did differ from one another in this region. On account of this interaction, the activation increase for the order inanimatebefore-animate $\left(\mathrm{S}_{\mathrm{I}} \mathrm{O}\right)$ in comparison to animate-before-inanimate $\left(\mathrm{OS}_{\mathrm{I}}\right)$ must be attributed to a violation of the animacy principle. Moreover, these data show that it is not the presence of an inanimate subject per se that leads to increased activation within the pars opercularis, but rather the relative ordering between animate and inanimate arguments.

These findings therefore support the linearization hypothesis of pars opercularis function that was first proposed in Bornkessel et al. (2005) and Grewe et al. (2005). This hypothesis postulates that the pars opercularis is sensitive to a range of principles determining linear order in a given language. As these linearization regularities (e.g. animacy) are drawn from a large body of languagecomparative research, they constitute a well-constrained set of principles governing word order preferences/rules in a wide range of languages (Comrie, 1989; Croft, 2003). While previous findings showed an influence of purely syntactic linearization principles (subject-before-object; Ben-Shachar et al., 2003, 2004; Caplan et al., 2000) or of principles at the interface between the syntax and other linguistic domains (thematic structure: Bornkessel et al., 2005; discourse saliency/phonological weight: Grewe et al., 2005), the present study is the first to provide evidence for the independent application of a purely semantic principle, namely animacy. Taken together, these findings indicate that the sequential order of arguments within a clause provides a melting pot for linearization parameters stemming from a variety of linguistic domains. ${ }^{5}$ This observation additionally serves to highlight how complex a task the language processing system must accomplish in performing the form-to-meaning mapping during efficient realtime communication, since information from these very different

\footnotetext{
${ }^{5}$ In fact, the scope of the linearization/sequencing capacity of the pars opercularis proper appears to extend to further domains of language processing. Gelfand and Bookheimer (2003) found an activation increase in Broca's area for the processing of phonemes and hummed notes in a sequence manipulation task compared to a match task. Thus, the observed activation increase in this cortical region might also be interpreted in terms of an engagement in general processes of hierarchical linearizing or sequencing.
} 
Table $3 b$

Talairach coordinates, maximal $z$ values and volumes of the activated region for the local maxima in the contrast between sentences with two animate arguments $\left(\mathrm{S}_{\mathrm{A}} \mathrm{O}\right.$ vs. $\left.\mathrm{OS}_{\mathrm{A}}\right)$ in an analysis including the mean reaction times per condition and participant as regressors

\begin{tabular}{llll}
\hline Region & Talairach coordinates & Max $z$ value & Volume $\left(\mathrm{mm}^{3}\right)$ \\
\hline L. superior occipital gyrus (19) & $-26-7518$ & 3.57 & 270 \\
R. basal ganglia (BG), putamen & 2830 & 3.77 & 729 \\
L. basal ganglia (BG), putamen & $-23-39$ & 3.66 & 378 \\
\hline
\end{tabular}

Only activations with a $z$ value $>3.09$ and a volume of at least $216 \mathrm{~mm}^{3}$ ( 8 measured voxels) were considered.

domains must be bound together and weighted appropriately in order for interpretation to be successful. ${ }^{6}$

In addition to providing more fine-grained evidence on the nature of the interaction of different linearization principles, the present study adds a further interesting dimension to the linearization hypothesis. Recall that, in contrast to previous studies, the animacy-induced activation observed here was very close to the inferior precentral sulcus, thereby engaging both the posterior portion of the pars opercularis and the anterior portion of the vPMC. On the one hand, this may have been due to a certain amount of interindividual variability: as revealed by our analysis of individual participant data, three participants showed an activation maximum at the border to ventral premotor cortex. A second possibility is that, on account of its primordial nature, the linearization rule examined here (animate-before-inanimate) may draw not only upon the highly abstract linearization properties represented in the pars opercularis, but also upon more basic sequencing operations supported by the ventral premotor cortex (Schubotz and von Cramon, 2003). Finally, it cannot be ruled out that the individual differences in the localization of the activation maximum may have resulted from differences in the processing strategy employed. Thus, activation of the precentral gyrus has been linked to aspects of motor planning in speech (see Dronkers, 1996; Riecker et al., 2005) and might therefore be indicative of inner speech. However, whether particular properties of individual linearization principles indeed manifest themselves in terms of subtle neuroanatomical distinctions - or strategic processing differences - must be investigated further in future research.

\footnotetext{
${ }^{6}$ Evidence for the impact of animacy in sentence comprehension also becomes apparent in aphasic patients. A study with aphasic speakers of Hindi investigating the relative ranking of three cues to agenthood (word order, noun animacy, and subject-verb agreement) indicates that these patients use animacy as the strongest feature in assigning grammatical roles (Vaid and Pandit, 1991). Interestingly, a strong effect of animacy has also been shown for aphasic speakers of Turkish (MacWinney et al., 1991). Animacy thus plays a stronger role than word order in Turkish and Hindi. Both of these languages are SOV languages and therefore comparable to German in that the noun phrases have to be interpreted before the verb is encountered. Thus animacy is used as a decisive feature in sentence interpretation here whereas SVO languages like English show a greater use of word order (MacWinney et al., 1991). Several further studies report a sensitivity of Broca's aphasics to animacy. Thus it was shown that the comprehension of inanimate constituent questions in French Broca's aphasics is worse than that of animate ones (Van der Meulen, 2004). For English Broca's patients it has also been found that inanimate constituent questions are more difficult to understand that their animate counterparts (Grodzinsky, 1995; Thompson et al., 1999). These findings thus provide converging support for the fundamental importance of animacy in sentence comprehension and its neurological relevance.
}

\section{Conclusions}

By manipulating the feature animacy in German ditransitive passive constructions, we were able to show that the pars opercularis of the left IFG is not only sensitive to syntactic linearization principles but also shows enhanced activation when a non-syntactic linearization rule is violated. The present data therefore demonstrate that the pars opercularis engages in a crucial aspect of the form-to-meaning mapping during sentence comprehension by reconstructing the interpretive status of sentential arguments from their linear position in the sentence. In addition to syntactic parameters (e.g. the subject-before-object principle), this reconstruction encompasses principles from further linguistic domains such as semantics. In this way, our findings demonstrate that approaches attempting to model sentence-level activation differences within the pars opercularis within a single linguistic domain fail to account for the full range of the data.

\section{Acknowledgments}

The research reported here was performed at the Max Planck Institute for Human Cognitive and Brain Sciences, Leipzig. Tanja Grewe acknowledges the support of the graduate program "Neuronal representations and action control" (GK 885/1) funded at the University of Marburg by the German Research Foundation (DFG). The authors would like to thank Angela Friederici for valuable discussions of the research reported here and Mandy Naumann, Annett Wiedemann and Simone Wipper for the data acquisition.

\section{References}

Aguirre, G.K., Zarrahn, E., d'Esposito, M., 1997. Empirical analyses of BOLD fMRI statistics: II. Spatially smoothed data collected under nullhypothesis and experimental conditions. NeuroImage 5, 199-212.

Bader, M., Meng, M., 1999. Subject-object ambiguities in German embedded clauses: an across-the board comparison. J. Psycholinguist. Res. 28, 121-143.

Ben-Shachar, M., Hendler, T., Kahn, I., Ben-Bashat, D., Grodzinsky, Y., 2003. The neural reality of syntactic transformations: evidence from fMRI. Psychol. Sci. 14, 433-440.

Ben-Shachar, M., Palti, D., Grodzinsky, Y., 2004. Neural correlates of syntactic movement: converging evidence from two fMRI experiments. NeuroImage 21, 1320-1336.

Bornkessel, I., Zysset, S., von Cramon, D.Y., Friederici, A.D., Schlesewsky, M., 2005. Who did what to whom? The neural basis of argument hierarchies during language comprehension. NeuroImage 26, 221-233.

Braver, T., Bongiolatti, S., 2002. The role of frontopolar cortex in subgoal processing during working memory. NeuroImage 15, 523-536.

Büring, D., 2001. Let's phrase it! Focus, word order and prosodic phrasing in German double object constructions. In: Müller, G., Sternefeld, W. 
(Eds.), Competition in Syntax. Mouton de Gruyter, Berlin/New York, pp. $69-105$.

Burock, M.A., Bruckner, R.L., Woldorff, M.G., Rosen, B.R., Dale, A.M., 1998. Randomized event-related experimental designs allow for extremely rapid presentation rates using functional MRI. NeuroReport 9, 3735-3739.

Caplan, D., Alpert, N., Waters, G., Olivieri, A., 2000. Activation of Broca's area by syntactic processing under conditions of concurrent articulation. Hum. Brain Mapp. 9, 65-71.

Chen, L., West, W.C., Waters, G., Caplan, D., to appear. Determinants of BOLD signal correlates of processing object-extracted relative clauses. Cerebral Cortex.

Chomsky, N., 1981. Lectures on Government and Binding. Foris Publications, Dordrecht.

Comrie, B., 1989. Language Universals and Linguistic Typology, 2nd ed. University of Chicago Press, Chicago.

Croft, W., 2003. Typology and Universals, 2nd ed. Cambridge Univ. Press, Cambridge.

Dronkers, N.F., 1996. A new brain region for coordinating speech articulation. Nature 384, 159-161.

Fiebach, C.J., Schlesewsky, M., Bornkessel, I., Friederici, A.D., 2004. Distinct neural correlates of legal and illegal word order variations in German: how can fMRI inform cognitive models of sentence processing. In: Carreiras, M., Clifton Jr., C. (Eds.), The On-Line Study of Sentence Comprehension. Psychology Press, New York, pp. 357-370.

Fiebach, C.J., Schlesewsky, M., Lohmann, G., von Cramon, D.Y., Friederici, A.D., 2005. Revisiting the localization of syntax: syntactic integration vs. syntactic working memory. Hum. Brain Mapp. 24, 79-91.

Forman, S., Cohen, J., Fitzgerald, M., Eddy, W., Mintun, M., Noll, D., 1995. Improved assessment of significant activation in functional magnetic resonance imaging (fMRI): use of a cluster-size threshold. Magn. Reson. Med. 33, 636-647.

Friederici, A.D., Rueschemeyer, S.-A., Hahne, A., Fiebach, C., 2003. The role of left inferior frontal and superior temporal cortex in sentence comprehension: localizing syntactic and semantic processes. Cereb. Cortex 13, 1047-3211.

Frisch, S., Schlesewsky, M., 2001. The N400 reflects problems of thematic hierarchizing. NeuroReport 12, 3391-3394.

Friston, K.J., Holmes, A.P., Worsley, K.J., Poline, J.-B., Frith, C.D., Frackowiak, R.W.J., 1995. Statistical parametric maps in functional imaging: a general linear approach. Hum. Brain Mapp. 2, 189-210.

Frith, C.D., Frith, U., 1999. Interacting minds-A biological basis. Science $286,1692-1695$.

Gelfand, J.R., Bookheimer, S.Y., 2003. Dissociating neural mechanisms of temporal sequencing and processing phonemes. Neuron 38, 831-842.

Gibson, E., 1998. Linguistic complexity: locality of syntactic dependencies. Cognition 68, 1-76.

Grewe, T., Bornkessel, I., Zysset, S., Wiese, R., von Cramon, D.Y., Schlesewsky, M., 2005. The emergence of the unmarked: a new perspective on the language-specific function of Broca's Area. Hum. Brain Mapp. 26, 178-190.

Grodzinsky, Y., 1995. Trace deletion, theta-roles, and cognitive strategies. Brain Lang. 51, 469-497.

Grodzinsky, Y., 2000. The neurology of syntax: language use without Broca's area. Behav. Brain Sci. 23, 1-71.

Holmes, A.P., Friston, K.J., 1998. Generalisability, random effects and population inference. NeuroImage 7, 754 .

Jackendoff, R., 1972. Semantic Interpretation in Generative Grammar. MIT Press, Cambridge, MA.

Jackendoff, R., 2002. Foundations of Language. Brain, Meaning, Grammar, Evolution. Oxford Univ. Press, New York.

Kaan, E., Swaab, T.Y., 2002. The brain circuitry of syntactic comprehension. Trends Cogn. Sci. 6, 350-356.

Keppel, G., 1991. Design and Analysis: A Researcher's Handbook, 3rd ed. Prentice Hall, Englewood Cliffs.

Lenerz, J., 1977. Zur Abfolge nominaler Satzglieder im Deutschen. Narr, Tübingen.
Lohmann, G., Müller, K., Bosch, V., Mentzel, H., Hessler, S., Chen, L., Zysset, S., von Cramon, D.Y., 2001. Lipsia-A new software system for the evaluation of functional magnetic resonance images of the human brain. Comput. Med. Imaging Graph. 25, 449-457.

MacWinney, B., Osman-Sagi, J., Slobin, D.I., 1991. Sentence comprehension in aphasia in two clear case-marking languages. Brain Lang. 41, $234-249$.

Miezin, F.M., Maccotta, L., Ollinger, J.M., Petersen, S.E., Buckner, R.L., 2000. Characterizing the hemodynamic response: effects of presentation rate, sampling procedure, and the possibility of ordering brain activity based on relative timing. NeuroImage 11, 735-759.

Müller, R.-A., Kleinhans, N., Courchesne, E., 2003. Linguistic theory and neuroimaging evidence: an fMRI study of Broca's area in lexical semantics. Neuropsychologia 41, 1199-1207.

Norris, D.G., 2000. Reduced power multi-slice MDEFT imaging. J. Magn. Reson. Imaging 11, 445-451.

Oldfield, R.C., 1971. The assessment and analysis of handedness: the Edinburgh Inventory. Neuropsychologia 9, 97-113.

Riecker, A., Wildgruber, D., Grodd, W., Ackermann, H., 2005. Functional magnetic resonance imaging studies on cerebral organization of speech motor control. Nervenheilkunde: Zeitschrift für interdisziplinäre Fortbildung 24, 177-183.

Röder, B., Stock, O., Neville, H., Bien, S., Rösler, F., 2002. Brain activation modulated by the comprehension of normal and pseudo-word sentences of different processing demands: a functional magnetic resonance imaging study. NeuroImage 15, 1003-1014.

Schubotz, R.I., von Cramon, D.Y., 2003. Functional-anatomical concepts of human premotor cortex: evidence from fMRI and PET studies. NeuroImage 20, 120-131.

Scott, S.K., Johnsrude, I.S., 2003. The neuroanatomical and functional organization of speech perception. Trends Neurosci. 26, 100-107.

Siwierska, A., 1988. Word Order Rules. Croom Helm, London.

Talairach, J., Tournoux, P., 1988. Co-Planar Stereotaxic Atlas of The Human Brain. Thieme, Stuttgart.

Thirion, J.P., 1998. Image matching as a diffusion process: an analogy with Maxwell's demons. Med. Image Anal. 2, 243-260.

Thompson, C.K., Tait, M.E., Ballard, K.J., Fix, S.C., 1999. Agrammatic aphasic subjects' comprehension of subject and object extracted whquestions. Brain Lang. 67, 169-187.

Tomaiuolo, F., MacDonald, J.D., Caramanos, Z., Posner, M., Chiavaras, M., Evans, A.C., Petrides, M., 1999. Morphology, morphometry and probability mapping of the pars opercularis of the inferior frontal gyrus: an in vivo MRI analysis. Eur. J. Neurosci. 11, 3033-3046.

Tomlin, R.S., 1986. Basic Word Order: Functional Principles. Routledge, London.

Ugurbil, K., Garwood, M., Ellermann, J., Hendrich, K., Hinke, R., Hu, X., Kim, S.-G., Menon, R., Merkle, H., Ogawa, S., Salmi, R., 1993. Imaging at high magnetic fields: initial experiences at 4T. Magn. Reson. Q 9, 259.

Vaid, J., Pandit, R., 1991. Sentence interpretation in normal and aphasic Hindi speakers. Brain Lang. 41, 250-274.

Van der Meulen, A.C., 2004. Syntactic Movement and Comprehension Deficits in Broca's Aphasia. LOT, Utrecht.

Van Valin, R.D., LaPolla, R., 1997. Syntax: Structure, Meaning and Function. University Press, Cambridge.

Weckerly, J., Kutas, M., 1999. An electrophysiological analysis of animacy effects in the processing of object relative sentences. Psycholophysiology $36,559-570$.

Wöllstein-Leisten, A., Heilmann, A., Stephan, P., Vikner, S., 1997. Deutsche Satzstruktur-Grundlagender syntaktischen Analyse. Stauffenburg, Tübingen.

Worsley, K.J., Friston, K.J., 1995. Analysis of fMRI time-series revisitedagain. NeuroImage 2, 173-181.

Zarahn, E., Aguirre, G.K., d'Esposito, M., 1997. Empirical analyses of BOLD fMRI statistics in spatially unsmoothed data collected under null-hypothesis conditions. NeuroImage 5, 179-197. 